Gut, 1988, 29, 789-794

\title{
Effect of jejunal infusion of bile acids on small bowel transit and fasting jejunal motility in man
}

\author{
R PENAGINI, J J MISIEWICZ, AND P G FROST \\ From the Department of Gastroenterology and Nutrition, and of Chemical Pathology, Central Middlesex \\ Hospital, London
}

SUMMARY The effect of jejunal infusion of glycochenodeoxycholic acid and glycocholic acid on small bowel transit time, fasting jejunal motility and serum bile acid concentrations was investigated in groups of five to six healthy subjects. Glycochenodeoxycholic acid at a concentration of $15 \mathrm{mmol} / \mathrm{I}$ (total amount: $5 \mathrm{mmol}$ ) and glycocholic acid $15 \mathrm{mmol} / \mathrm{l}$ (total amount: $5 \mathrm{mmol}$ ), both with lecithin $2 \cdot 5$ $\mathrm{mmol} / \mathrm{l}$, delayed $(\mathrm{p}<0 \cdot 02)$ small bowel transit when compared with a bile acid free infusion [158.3 $(12.5) \mathrm{min} v 111.7(17.6) \mathrm{min}$ and $103.3(21.8) \mathrm{min} v \mathbf{7 0 . 0}(14.9) \mathrm{min}]$, inhibited $(\mathbf{p}<0.01$ and $\mathbf{p}<0.05$ respectively) the percentage duration of pressure activity of phase $2[13 \cdot 1(1.8) \% \vee 28 \cdot 1(3.4) \%$ and $29.2(5.5) \% \vee 34.9(3.9) \%$ ], but did not change duration of migrating motor complex, or of its phases. Glycochenodeoxycholic acid $10 \mathrm{mmol} / \mathrm{l}$ (total amount: $3 \cdot 3 \mathrm{mmol}$ ), either with or without lecithin, did not delay small bowel transit significantly [145.0 (13.2) $\min v 115.0(19 \cdot 5)$ and 90.0 $(11 \cdot 7) \mathrm{min} v 84 \cdot 0(8 \cdot 3)]$. When bile acids were infused, serum bile acid curves were similar to those obtained after a liquid meal and the peak serum bile acid concentration occurred $33.7(6.6) \mathrm{min}$ before $(p<0.001)$ completion of small bowel transit. These observations suggest a role for endogenous bile acids in the regulation of small gut motility.

Bile acids and bile have been claimed to have stimulatory effects on small intestinal motility and transit, but data are discordant ${ }^{1-5}$ and no observations are available in man. Dihydroxy bile acids have been shown to inhibit water and electrolyte absorption in the human jejunum ${ }^{6}$ and ileum $^{7}$ and oral intake of chenodeoxycholic acid for dissolution of gall stones gives rise to diarrhoea in a considerable number of patients. ${ }^{x-9}$ The effect is thought to be because of a direct secretory action of the dihydroxy bile acid on colonic mucosa ${ }^{11}$ but an increased ileal flow and rapid small intestinal transit may be contributory factors."

The present study was designed to clarify whether bile acids affect small bowel motility and transit. Bile acids were administered in physiological amounts and in most experiments lecithin was added to the infused solutions to mimic endogenous input of bile acids which occurs in the physicochemical state of mixed micelles.

Address for correspondence: Dr R Penagini, Cattedra di Patologia Medica III Istituto di Scienze Mediche, Pad Granelli, Via F Sforza. 35, 20122 Milano. Italy.

Received for publication 21 January 1988.
Methods

SUBJECTS

Eighteen healthy subjects (aged 19-32 years, 15 men) entered the study which was approved by the Brent Health District Ethical Committee. Women were studied in the follicular phase of the menstrual cycle.

EXPERIMENTAL DESIGN

Each subject underwent measurement of the small bowel transit time (SBTT) of lactulose during jejunal infusion of saline alone and during infusion of at least one of four solutions containing either glycochenodeoxycholic acid (GCDC) or glycocholic acid (GC) in amounts comparable with an average bile acid pool, ${ }^{12}{ }^{13}$ as described in Table 1 . Throughout this study the concentration of the bile acids infused is expressed in $\mathrm{mmol} / \mathrm{l}$ and the total amount administered in mmol. Fourteen subjects were infused with one bile acid solution only, four were infused with two bile acid solutions: one with GCDC $10 \mathrm{mmol} / \mathrm{l}$ 
Table 1 Solutions used during all experiments. Concentrations of infusates are expressed in mmolll, with total amounts in brackets

- Saline $(n=18)$

- Saline +GCDC* $10 \mathrm{mmol} / \mathrm{l}(3 \cdot 3 \mathrm{mmol})(\mathrm{n}=5)$

- Saline + GCDC $10 \mathrm{mmol} / \mathrm{l}(3 \cdot 3 \mathrm{mmol})+$ lecithin $† 2 \cdot 5 \mathrm{mmol} / \mathrm{l}(\mathrm{n}=5)$

- Saline+GCDC $15 \mathrm{mmol} / \mathrm{l}(5 \mathrm{mmol})+$ lecithin $2.5 \mathrm{mmol} / \mathrm{l}(\mathrm{n}=6)$

- Saline + GC $\ddagger 15 \mathrm{mmol} / \mathrm{l}(5 \mathrm{mmol})+$ lecithin $2.5 \mathrm{mmol} / \mathrm{l}(\mathrm{n}=6)$

${ }^{*}$ Glycochenodeoxycholic acid, as sodium salt. Sigma Chemical Company Ltd, $98 \%$ pure; †BDH Chemicals Ltd, $90 \%$ pure (chief contaminants: sulphated ash, nitrogen, phosphorus); $\ddagger$ glycocholic acid, as sodium salt, Sigma Chemical Company Ltd, $99 \%$ pure.

One subject was studied during infusions of GCDC $10 \mathrm{mmol} / \mathrm{l}$ and GCDC $10 \mathrm{mmol} / \mathrm{l}+$ lecithin on separate occasions; three subjects were studied during infusion of GCDC $15 \mathrm{mmol} / \mathrm{l}+$ lecithin and GC $15 \mathrm{mmol} / \mathrm{l}+$ lecithin on separate occasions.

and GCDC $10 \mathrm{mmol} / \mathrm{l}+$ lecithin (L) and three with GCDC $15 \mathrm{mmol} / \mathrm{l}+\mathrm{L}$ and GC $15 \mathrm{mmol} / \mathrm{l}+\mathrm{L}$. Each solution was infused on a separate day in randomised order. To avoid stimulation of endogenous bile acid secretion by feeding, the subjects were studied in the fasted state.

The subjects were instructed to limit their meals from lunchtime on the day before each study to those foodstuffs which result in little, or no rise in breath hydrogen (rice and meat). After an overnight fast, all subjects swallowed an assembly of polyvinyl tubes weighted at the end with a double balloon containing $1 \mathrm{ml}$ mercury. The assembly contained one radioopaque tube to facilitate fluoroscopic localisation. When the assembly entered the duodenum a small amount of air was injected into the terminal balloon to accelerate intubation, until the infusion port, marked by a small radio-opaque plug, was placed 10 $\mathrm{cm}$ beyond the duodenojejunal flexure. The balloon was then deflated and the mercury completely aspirated.

In the experiments testing GCDC $10 \mathrm{mmol} / \mathrm{l} \pm \mathrm{L}$ $(n=10)$ the tube assembly consisted of two single lumen tubes (external diameter $=2 \mathrm{~mm}$ ), one for infusion and one for balloon inflation. In the 12 experiments testing GCDC $15 \mathrm{mmol} / \mathrm{l}+\mathrm{L}$ and GC 15 $\mathrm{mmol} / \mathrm{l}+\mathrm{L}$ a three lumen (external diameter $=2 \mathrm{~mm}$ ) tube (Dural Plastics, Australia) was added to measure jejunal intraluminal pressures at 5,20 , and $35 \mathrm{~cm}$ beyond the infusion port. The three manometry tubes were continuously perfused with water at $0 \cdot 15$ $\mathrm{ml} / \mathrm{min}$ by a low compliance pneumohydraulic capillary infusion system (Mui Scientific), permitting a response time of $35 \mathrm{mmHg} / \mathrm{sec}$. The tubes were connected to external pressure transducers (Statham p23ID) and signals recorded on a polygraph (Grass, model 7). A further polygraph channel monitored respiration through a pneumatic belt placed round subjects' chest.
When the tube assembly was in place, a cannula was inserted into a forearm vein using local anaesthetic and kept patent with heparinised saline. After one hour's rest in the experiments testing GCDC 10 $\mathrm{mmol} / \mathrm{l} \pm \mathrm{L}$, and after appearance of phase 3 of a migrating motor complex (MMC) detected by the three manometry ports in the experiments testing GCDC $15 \mathrm{mmol} / \mathrm{l}+\mathrm{L}$ and GC $15 \mathrm{mmol} / \mathrm{l}+\mathrm{L}$, the study started as described in Figure 1. In one subject who did not have phase $3 \mathrm{MMC}$ after four hours of recording on the first study day, GC and control study were performed starting in phase 2 without waiting for an activity front.

Solutions described above were infused at $3 \mathrm{ml} / \mathrm{min}$ using an infusion pump (MHRE Mk4 Flow Inducer, Watson-Marlow Ltd, England) for 80 minutes. Simultaneously saline for the first $\mathbf{3 0}$ minutes, and a solution containing lactulose $5 \mathrm{~g}$ for the following 50 minutes was infused at $1 \mathrm{ml} / \mathrm{min}$. This quantity of lactulose was approximately equivalent to unabsorbed carbohydrate after an ordinary meal..$^{1+}$ All infusates were iso-osmotic and $\mathrm{pH}$ was adjusted to $7 \cdot 0$ using $\mathrm{NaOH}$.

\section{MEASUREMENT OF BREATH HYDROGEN}

Using a modified Haldane Priestley tube, end expiratory breath samples were taken every five minutes from the beginning of the infusion for 150 minutes, or until a sustained hydrogen concentration rise was detected in breath.

Breath hydrogen was measured using an electrochemical detector (GMI, Renfrew, Scotland) with a sensitivity of $2 \mathrm{ppm}$ and an accuracy of $\pm 2 \%$. Small bowel transit time was defined as time elapsed when increase of breath hydrogen of at least $3 \mathrm{ppm}$ above baseline occurred, continuing to rise for at least 30 minutes.

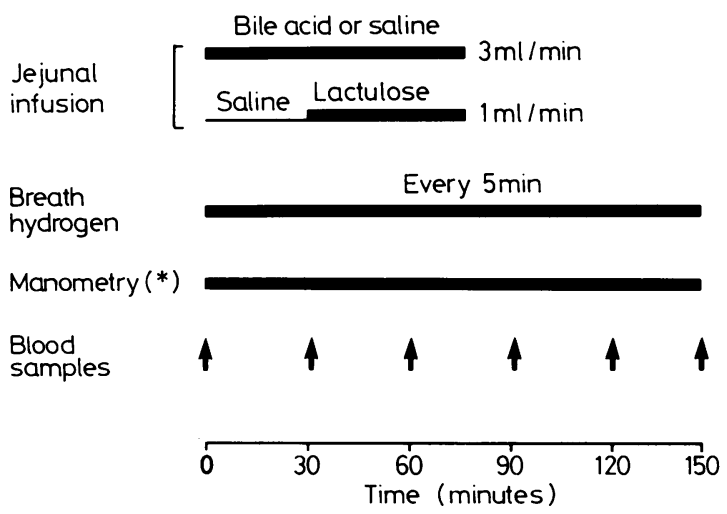

Fig. 1 Diagram illustrating the protocol of all experiments. $\left({ }^{*}\right)$ in the experiments testing glycochenodeoxycholic acid 15 mmol/l+lecithin and glycocholic acid $15 \mathrm{mmol} / \mathrm{l}+$ lecithin only $(n=12)$. 
MEASUREMENT OF SERUM BILE ACIDS

Blood samples were taken at $0,30,60,90,120,150$ minutes for measurement of total bile acids in the experiments using GCDC and cholylglycine in the experiments using GC (Fig. 1). Total bile acids were measured by direct spectrophotometry (Enzabile, Nyegaard) using an automatic analyser (Cobas Mira, Roche) with a good reproducibility $(\mathrm{CV}=4.1 \%$; $\mathrm{n}=10$ ). Cholylglycine was measured using a specific radioimmunoassay (CG RIA, Abbott Diagnostics), giving a $\mathrm{CV}$ of $3 \cdot 8 \%(n=10)$. For total bile acids and cholylglycine, peak incremental response (PIR) and integrated incremental response (IIR $=$ area under the curve taking the basal value as zero) were calculated.

ANALYSIS OF PRESSURE RECORDS

After Kerlin and Phillips, ${ }^{15}$ phase 1 was defined as quiescence, phase 2 as intermittent activity and phase 3 as three minutes or more of uninterrupted rhythmic contractions, followed by quiescence. Migration required the recording of phase 3 activity successively from all three recording ports. Migrating motor complexes were defined as starting at the end of a migrated phase 3 and terminating at the end of the next one. All pressure tracings were blindly measured by one of the authors. Tracings were quantitatively analysed with respect to duration of MMC and its phases, and with respect to percentage duration of pressure activity during phase 2 . The latter variable was calculated for each experiment as a whole and divided into 30 min epochs. In addition tracings were qualitatively analysed for presence of specific patterns of contractions, defined according to Summers et al. ${ }^{16}$

Calculations of percentage duration of pressure activity during phase 2 were carried out twice $(n=21)$, giving a CV of $3 \cdot 5 \%$.

STATISTICAL ANALYSIS

Results, expressed as mean (SE), were analysed using Student's $t$ test.

\section{Results}

SMALL BOWEL TRANSIT TIME

Solutions containing GCDC $15 \mathrm{mmol} / \mathrm{l}$ and GC 15 $\mathrm{mmol} / \mathrm{l}$ significantly prolonged SBTT $[158 \cdot 3(12 \cdot 5) v$ $111.7(17 \cdot 6)$ and $103.3(21.8) v 70 \cdot()(14 \cdot 9), \mathrm{p}<0 \cdot(02]$. Solutions containing GCDC $10 \mathrm{mmol} / \mathrm{l}$ either with or without lecithin had a less consistent effect on SBTT $[145 \cdot 0(13 \cdot 2) \vee 115.0(19.5)$ and 90.() (11.7) $v 84 \cdot()$ $(8 \cdot 3), \mathrm{p}=\mathrm{ns}]$ (Fig. 2).

MOTILITY

Duration of MMC and of its phases was not altered significantly by infusions of GCDC $15 \mathrm{mmol} / \mathrm{l}$ and GC $15 \mathrm{mmol} / \mathrm{l} \mathrm{GC}$ (Fig. 3). Infusion with GCDC 15 $\mathrm{mmol} / \mathrm{l}$ produced decreased pressure activity during phase 2 and this reduction appeared to be more marked than that due to GC $15 \mathrm{mmol} / \mathrm{l}$, when compared with saline [Fig. $4 ; 13 \cdot 1(1 \cdot 8) \%$ v $28 \cdot 1$

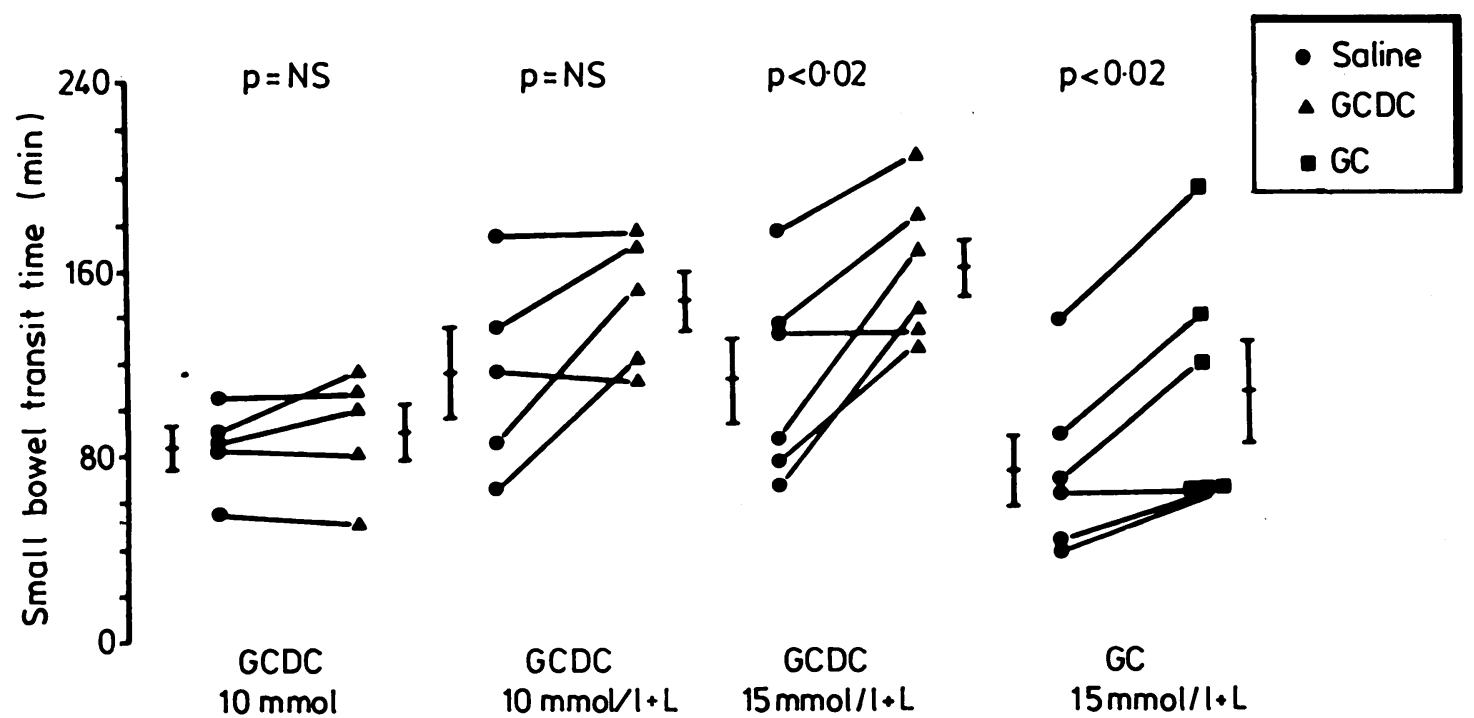

Fig. 2 Small bowel transit time of lactulose when the jejunum of healthy volunteers was infused with saline (O), GCDC

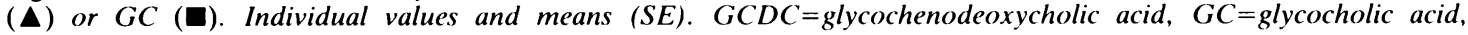
$L=$ lecithin. 


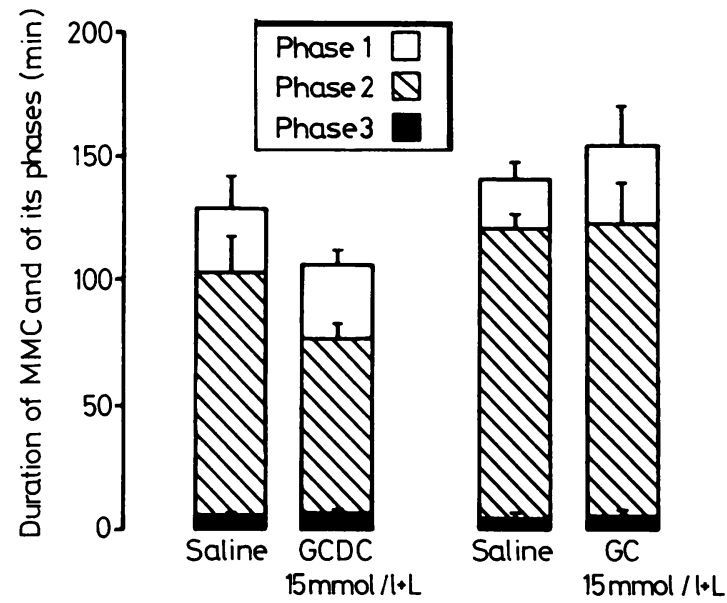

Fig. 3 Duration of migrating motor complex (MMC) and of its phases when the jejunum of healthy volunteers was infused with saline, GCDC $15 \mathrm{mmol} / \mathrm{l}+\mathrm{L}$ or GC 15 mmolll+L. [means $(S E)] . G C D C=$ glycochenodeoxycholic acid, $G C=$ glycocholic acid, $L=$ lecithin.

$(3.4) \%, p<0.01$ and $29.2(5.5) \% \vee 34.9(3.9) \%$, $\mathrm{p}<0.05$ respectively]. Dividing the analysis of phase 2 pressure activity in $30 \mathrm{~min}$ epochs, it is apparent that inhibition of activity by GCDC (Fig. 5) was not immediate and persisted in all subjects after the infusion ended $(p<0.05)$. When 30 min epochs were sampled for the GC studies, a lower mean pressure activity of phase 2 was seen along the whole of the GC experiment compared to saline, but the difference failed to reach statistical significance in any of the epochs. Qualitative analysis of pressure records showed runs of discrete clustered contractions in three subjects during saline infusion (occupying $7 \cdot 6 \%$ to $18.5 \%$ of total duration of phase 2 ), in no subject during GCDC infusion and in two subjects during GC infusion (occupying $11.7 \%$ and $15.3 \%$ of phase 2).

\section{SERUM BILE ACIDS}

Compared with saline, total bile acid and cholylglycine IIR and PIR were significantly $(p<0.05)$ higher after all solutions containing bile acids (Table $2)$. Considering all the 22 infusions of bile acids together, the peak serum bile acid concentration occurred $33.7(6 \cdot 6)$ minutes before $(p<0 \cdot 001)$ the rise in breath hydrogen. In particular peak serum bile acid concentration preceded the arrival of lactulose in the caecum in 17 of the 22 infusions.

\section{Discussion}

Bile acids are generally considered to have a stimulatory effect on gut motility and transit. The present

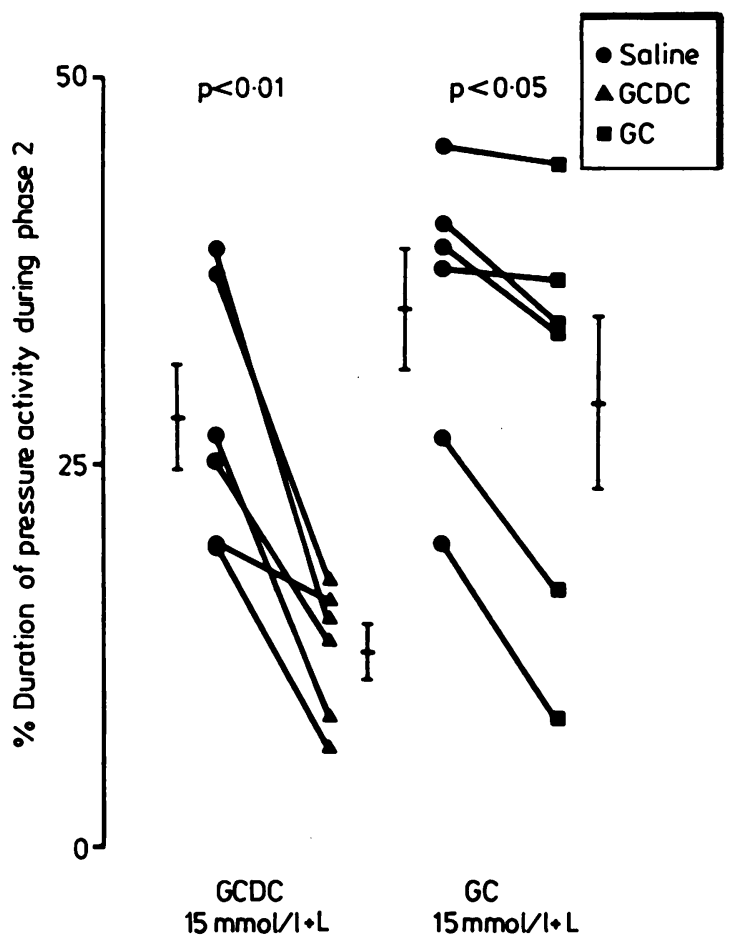

Fig. 4 Percentage duration of pressure activity of phase 2 of migrating motor complex when the jejunum of healthy volunteers was infused with saline (O), GCDC $15 \mathrm{mmol} / \mathrm{l}+L$ (A) or GC $15 \mathrm{mmol} / \mathrm{l}+L(\mathbf{\square})$. Individual values and means (SE). GCDC=glycochenodeoxycholic acid, $G C=$ glycocholic acid, $L=$ lecithin.

study suggests that the subject is probably more complicated than previously thought. Glycochenodeoxycholic acid and GC, the two main forms of primary bile acids present in human bile, ${ }^{17}$ when infused in the jejunum of healthy man did not stimulate motility. On the contrary, at a concentration of $15 \mathrm{mmol} / \mathrm{l}$ (total amount of $5 \mathrm{mmol}$ ) they appeared to decrease jejunal intraluminal pressures and delay SBTT. In contrast with previous animal studies ${ }^{4-5}$ bile acids were infused in the present study at a physiological rate ${ }^{1218}$ and concentration, ${ }^{19}$ comparable with the postprandial state. The serum bile acid curves, which were similar to those obtained after a $440 \mathrm{kcal}$ liquid meal ${ }^{20}$ support this contention. The effect on SBTT appeared to be dependent on the bile acid concentration and/or rate of infusion, because GCDC $10 \mathrm{mmol} / \mathrm{l}$ did not produce significant slowing of transit. Although it cannot be excluded that delay in breath hydrogen rise was due to an effect of bile acids entering the large bowel on hydrogen production, this possibility is unlikely as we have shown bile acids to have an inhibitory effect on small 


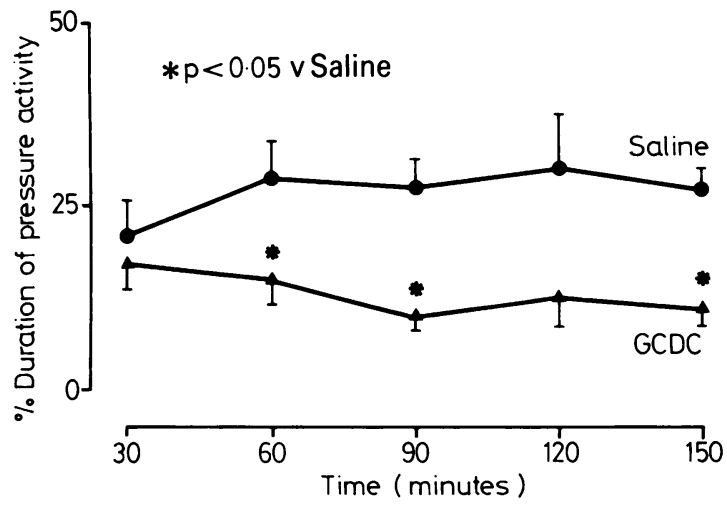

Fig. 5 Percentage duration of pressure activity of phase 2 of migrating motor complex when the jejunum of healthy volunteers was infused with saline (O) or GCDC 15 mmolll+L (A) [means (SE)]. Analysis in 30 min epochs. $G C D C=$ glycochenodeoxycholic acid, $L=$ lecithin .

intestinal transit also using a dye dilution technique (unpublished data).

The reason why bile acids slowed SBTT and inhibited motility is unknown. A few observations, however, shed some light on the possible mechanism. First, in the GCDC $15 \mathrm{mmol} / \mathrm{l}$ experiments where inhibition of motility was more marked, it was clear (Fig. 5) that decrease in intraluminal pressure activity was delayed with respect to the start of the GCDC infusion. Second, unpublished work in our laboratory investigating the effect of ileal infusion of GCDC on the jejunum and the ileum, showed a pattern of inhibition of jejunal motility similar to the one observed in the present study and a strikingly immediate inhibition in motility in the ileum exposed to the infused GCDC. These observations lead us to the hypothesis that the inhibitory responses recorded in the present study are mediated through bile acid

Table 2 Serum bile acid concentrations during all experiments: means (SE)

\begin{tabular}{|c|c|c|c|}
\hline & $\begin{array}{l}\text { Fasting } \\
(\mu \text { molll })\end{array}$ & $\begin{array}{l}P I R \\
(\mu \mathrm{mol} / \mathrm{l})\end{array}$ & $\begin{array}{l}I I R \\
(\mu \mathrm{mol} / \mathrm{l}-\mathrm{h})\end{array}$ \\
\hline $\begin{array}{l}\text { GCDC } 10 \mathrm{mmol} / \mathrm{l} \\
\text { saline }\end{array}$ & $\begin{array}{l}1 \cdot 8(0 \cdot 5) \\
1 \cdot 6(0 \cdot 4)\end{array}$ & $\begin{array}{l}5 \cdot 2(1 \cdot 6)^{*} \\
0 \cdot 4(0 \cdot 4)\end{array}$ & $\begin{array}{l}150 \cdot 6(53 \cdot 7)^{*} \\
-6 \cdot 3(16 \cdot 8)\end{array}$ \\
\hline $\begin{array}{l}\mathrm{GCDC} 10 \mathrm{mmol} / \mathrm{l}+\mathrm{L} \\
\text { saline }\end{array}$ & $\begin{array}{l}1 \cdot 6(0 \cdot 2) \\
2 \cdot 3(0 \cdot 6)\end{array}$ & $\begin{array}{l}6 \cdot 0(1 \cdot 3)^{*} \\
1 \cdot 5(0 \cdot 5)\end{array}$ & $\begin{array}{c}163 \cdot 7(39 \cdot 9)^{*} \\
13 \cdot 0(15 \cdot 0)\end{array}$ \\
\hline $\begin{array}{l}\mathrm{GCDC} 15 \mathrm{mmol} / \mathrm{l}+\mathrm{L} \\
\text { saline }\end{array}$ & $\begin{array}{l}2 \cdot 3(0 \cdot 2) \\
3 \cdot 2(0 \cdot 3)\end{array}$ & $\begin{array}{l}9 \cdot 7(4 \cdot 5)^{*} \\
0 \cdot 4(0 \cdot 3)\end{array}$ & $\begin{array}{l}219 \cdot 6(100 \cdot 6)^{*} \\
-19 \cdot 6(8 \cdot 2)\end{array}$ \\
\hline $\begin{array}{l}\text { GC } 15 \mathrm{mmol} / \mathrm{l}+\mathrm{L} \\
\text { saline }\end{array}$ & $\begin{array}{l}0 \cdot 10(0 \cdot 07) \\
0 \cdot 11(0 \cdot 03)\end{array}$ & $\begin{array}{l}4.4(1 \cdot 5)^{*} \\
0 \cdot 2(0 \cdot 1)\end{array}$ & $\begin{array}{c}104.9(29 \cdot 7)^{*} \\
3.9(2 \cdot 4)\end{array}$ \\
\hline
\end{tabular}

${ }^{*}=$ different from control $(p<0 \cdot 05)$. GCDC $=$ glycochenodeoxycholic acid. $\mathrm{GC}=$ glycocholic acid. $\mathrm{L}=$ lecithin. specific chemoreceptors located in the ileum. The inhibition of motility may favour absorption of bile acids and minimise their escape into the large bowel. This hypothesis is supported by the fact that peak serum bile acid concentration occurred during most infusions containing bile acids before lactulose reached the caecum, suggesting that transit might have been in some way dependent on absorption of bile acids.

The presence of lecithin has been shown to abolish the inhibitory effect of dihydroxy bile acids on water and electrolyte absorption from the human jejunum, probably by decreasing the concentration of bile acids in monomeric form. ${ }^{6}$ In the present study most of the experiments were done with lecithin added to the infused bile acids, to avoid unphysiological jejunal secretion and mimic endogenous input. Because GCDC was infused in monomeric form only at a concentration $(10 \mathrm{mmol} / \mathrm{l})$ ineffective on SBTT, our experiments could not clarify whether the effect of bile acids on small bowel motility and transit is influenced by their physicochemical state.

\section{References}

1 Haney HF, Roley WC, Cole PA. The effect of bile on the propulsive motility of Thiry-Vella loops in dogs. Am J Physiol 1939; 126; 82-8.

2 Ackerman RF, Curl H, Crandall LA. Gastrointestinal tract motility in the absence of bile. Am J Physiol 1941; 134: 32-6.

3 Morgan RGH, Simmonds WJ. The relative effects of diversion of bile to the ileum or to the urinary bladder on fat absorption and gastrointestinal motility in the rat. QJ Exp Physiol 1962; 47: 352-9.

4 Feldman S, Gibaldi M. Effect of bile salts on gastric emptying and intestinal transit in the rat. Gastroenterology 1968; 54: 918-21.

5 Kruis W, Azpiroz F, Phillips SF. Contractile patterns and transit of fluid in canine terminal ileum. Am J Physiol 1985; 249: G264-70.

6 Wingate DL, Phillips SF, Hofmann AF. Effect of glycine-conjugated bile acids with and without lecithin on water and glucose absorption in perfused human jejunum. J Clin Invest 1973; 52: 1230-6.

7 Krag E, Phillips SF. Effect of free and conjugated bile acids on net water, electrolyte, and glucose movement in the perfused human ileum. J Lab Clin Med 1974; 83: 947-56.

8 Schoenfield LJ, Lachin JM, Baum RA, et al. Chenodiol (chenodeoxycholic acid) for dissolution of gallstones: the National Cooperative Gallstone Study. Ann Intern Med 1981; 95: 257-82.

9 Tangedahl T, Carey WD, Ferguson DR, et al. Drug and treatment efficacy of chenodeoxycholic acid in 97 patients with cholelithiasis and increased surgical risk. Dig Dis Sci 1983; 28: 545-51.

10 Meckhjian HS, Phillips SF, Hofmann AF. Colonic secretion of water and electrolytes induced by bile acids: perfusion studies in man. J Clin Invest 1971; 50: $1569-77$. 
11 MacGregor IL, Wiley ZD, Sleisinger MH. The role of bile acids in determining ileal flow rates in normal subjects and following ileostomy. Digestion 1978; 18: 192-200.

12 Brunner H, Northfield TC, Hofmann AF, Go VLW, Summerskill WHJ. Gastric emptying and secretion of bile acids, cholesterol, and pancreatic enzymes during digestion. Mayo Clin Proc 1974; 49: 851-9.

13 Roda E, Aldini R, Mazzella A, et al. Enterohepatic circulation of bile acids after cholecystectomy. Gut 1978; 19: 640-9.

14 Stephen AM, Haddad AC, Phillips SF. Passage of carbohydrate into the colon. Direct measurements in humans. Gastroenterology 1983; 85: 589-95.

15 Kerlin P, Phillips SF. Variability of motility of the ileum and jejunum in healthy man. Gastroenterology 1982; 82: 694-700.
16 Summers RW, Anuras S, Green J. Jejunal manometry patterns in health, partial intestinal obstruction, and pseudoobstruction. Gastroenterology 1983; 85: 1290-300.

17 Hofmann AF. The enterohepatic circulation of bile acids in man. In: Paumgartner G. ed. Clinics in gastroenterology. Vol 6. Bile acids. London: WB Saunders Company, 1977: 3-24.

18 Malagelada JR, Go VLW, Summerskill WHJ. Different gastric, pancreatic, and biliary responses to solid-liquid or homogenized meals. Dig Dis Sci 1979; 24: 101-10.

19 Fordtran JS, Locklear TW. Ionic constituents and osmolality of gastric and small intestinal fluids after eating. Am J Dig Dis 1966; 11: 503-21.

20 Penagini R, Spiller RC, Misiewicz JJ, Frost PG, Silk DBA. Effect of cholecystectomy on mouth-to-caecum transit of a liquid meal. Dig Dis Sci 1988; 33: 19-22. 